\title{
Science, As a Universal Tale
}

\author{
Hossein Falsafi ${ }^{1, *}$ \\ ${ }^{1}$ Department of the Islamic Wisdom and Philosophy, Khorramabad Branch, Islamic Azad University, Khorramabad, \\ Iran \\ *Correspondence: Department of the Islamic Wisdom and Philosophy, Khorramabad Branch, Islamic Azad \\ University, Khorramabad, Iran. E-mail: falsafi.1584@yahoo.com
}

Received: July 4, 2019 Accepted: August 9, 2019 Online Published: September 19, 2019

doi:10.5430/sass.v6n2p88 URL: https://doi.org/10.5430/sass.v6n2p88

\begin{abstract}
In This thesis I will account from inductivism and its problem and its successors like falsificationism, structures of science and against method, at first; and then, I will prove that "science is a tale."
\end{abstract}

Keywords: science, tale, theory, struggle, hero

\section{Preface}

Science is a kind of knowledge. This knowledge by great changes in physics, astronomy and so on and also because of articulating various and wonderful products such as telescope and microscope and so on was considered and ascended eternally to the throne like a king, on the late 16th century and the early of 17th century. Francis Bacon (1562-1626) is the founder of science. He knows this science as an ability. In this view science stands on the two pillars: observation and induction (Ladyman, 2002, p. 27)

After passing happy days, defects of science was clear and it was observed that science is only a general and agreeable tale like ancient tales. For proving this, at first, we will speak about inductivism and its problems and successors; after that by investigation the quality of a tale and its various parts we will prove that "science is only a tale!"

\section{The First Part: A) Inductivism and Its Problems and Successors}

\subsection{Inductivism}

We said that the modern knowledge is based on two pillars in the view of Bacon: observation and induction. Science theories are derived through observation and experiment of facts of experience; for example, when you boil some water in glasses of number one, two, and three and so on, by observing its result you derive this theory that" every water boils at 100 degrees." Boiling water in glasses of number one, two, three and so on is accounted by statements with the name of "Singular statements". These statements are the tenets of theories and laws and every observer can articulate their accuracy by application of his observing organs without any mediator (Burtt, 1990, p. 36 and 37)

Such observation is called a naive inductivism which has many problems with itself. For instance, we cannot derive a general statement from inadequate singular statements which are trivial in comparison with probable statements. Inductivists assert that we can do it provided these three conditions. First, high frequency of observing statements, second, variety of conditions where an experiment is performed there and third, no one of singular statements are incompatible with a derived universal law(Chalmers, 1976, p.4). Regarding to these three conditions, inductivists believe that "if a large number of Ps have been observed under a wide variety of conditions, and if all those observed As without exception have possessed the property B, then all As possess the property B (Ibid, p. 5). This method that generalizes from a finite list of singular statements to a universal low is called inductive reasoning.

\subsection{Problems of Inductivism}

Inductivis has many problems here are some brief Hume's strong objections. 1) Logical inaccuracy of induction: The great throne of knowledge is based on induction and it is very useful. Logic makes claims that if introduction of a 
reasoning is accurate, thus its result would be accurate. This is a true statement in deduction, but not in induction .Introductions of inductive reasoning probably is true, but its result is not true free from incompatibility. Now, it is a question whether on logical ground, it can be resulted from boiling thousands of glasses of water with approach to three mentioned grounds that "every water boils at 100 degrees ". Of course it is not true. Consequently, induction cannot be justified purely on logical ground (Ladyman, 2002, pp, 35-38). 2) Experimental inaccuracy of induction: Some of inductivists believe that induction is always succeed because it is successful in many places. To prove the accuracy of induction by experiment is not true perfectly because reasoning of proving the accuracy of induction by experiment necessitated circle because this reasoning for proving the accuracy of induction uses the very same inductive reasoning which need to be proved itself (Ibid, p. 39). Scientists divided into two groups after Hume's strong objections.

1) Some of more mature inductivisms attempt to facilitate inductive reasoning by modifying it. They take into account science as a knowledge which is probably true. Here is the Abstract of ad hoc modification reasoning:" if a large number of As have been observed under a wide variety of conditions, and if all those observed As possess the property B, then all As possess probably the property B" (Chalmers, 1976, p. 4). But this modified reasoning cannot conclude the problem of induction. Because it is also a general statement and its failure is constant yet.

2) Another problem is that an inductivist arrive at laws by observation and it has always many problems because it may keep company with many failures. "A white, connected and unmovable sheet" which is observed by observer is never white, connected or even unmovable indeed! Because we know that there is no color out of mind and a the sheet is made from many movable atoms and these never connect to each other. So, this sheet is not the very same thing that observing of everything is different from someone to someone else and an observer probably observes a thing differently on various times.

1) Falsificationism

Inductivism was not beneficial and it was the reason of creation of falsificativism .In the view of falsificationists, observation is heuristed and presupposed by a theory. They abandon any claim that theories can be established as true or probably true in the light of observational evidences. They suppose that theories are proved as inconstant conjectures created by scientists in an attempt to account some aspects of the nature. These speculative theories (conjectures) are to be roughly tested by experiment and theories that are lose must be abandoned and lose out to novel speculative conjectures, finally.

It is true that we may not arrive at universal laws and theories by true observation statements but we legitimately find out universal laws and theories are not true. It means that the universal statement "all ravens are black." can be shown to be false by observing a white raven. Falsificationists never legitimately say this or that theory is true however, in their view, every successful theory is in comparison with a previous unsuccessful one is successful.

There are further criticisms facing falsificationism. The most important of those criticisms is about observation statements. Because in their view point, observation statements which falsify conjectures are falsifiable statements themselves. We are not able to falsify a theory by a falsifiable statement because such mater caused to logical circle, in view of the fact that failure of an observation statement which falsifies the theory may probably be clear up. Acceptance of fundamental statements depends on desires or the wills of scientists (Popper, 1991, p. 145). The history of science articulates the falsity of this view because some theories of science were incompatible with observation but they are not abandoned theories.

\section{2) Research Programs}

This is Thomas Kuhn's view of science. In his view, whether or not one theory is better than another on behalf of individual scientists or groups does not show the accuracy or falsity of those paradigms. It means that the acceptance of a paradigm dose not relatives to the standards and choices of scientists and groups (Chalmers, 1976, p. 89).

These are the stages of progress of science in Kuhn's view: background knowledge, science, normality, crisis, revolution, novel and normal science, novel crisis (Losee, 2001, p. 272-6).

There is not a theory in background knowledge and also a theory was created by scientist's mental structures. One of the characteristics of the background knowledge is popular incompatibility and struggle for tenets as far as it changes a wide and difficult subject to an impossible one. In background knowledge the rival theoreticians disagreed not only on fundamental theoretical hypotheses but also on some kinds of observational affair, which were depend on their theories as far as Kuhn acknowledged the role of paradigm on the research heuristic for accounting states of observational affairs. He often agreed with "the relativity of theory to observations. 
There are always abnormalities which confronted paradigms with many problems. In some special conditions, the abnormalities increase so that is it eliminates the assurance to the paradigm. A special problem will occur if the abnormality eliminates the tenets of a paradigm and persist obstinately against all endeavors of a normal scientific community for abandoning that abnormality. Bad conclusion of crisis is seen and advanced when a rival paradigm is created. A novel paradigm differs from the olden one and this is compatible with that, sideways.

There is no reasoning - which is only on logic - That elucidates one paradigm is better that another. There is not any inductive method which derives us to the most appropriate paradigms. Consequently, science must has different means for selection appropriate theory and abandon other rival theories, and this theis application of revolution.

All paradigms are somewhat compatible with the nature. With advance of crisis and growth of incompatibility the step of revolution of losing out of whole that paradigm with another one is necessitated for scientific progress and advance.

\section{3) Against Method}

This is the view of Paul Feyerabend. He believes that science breaks the rules and he takes into account disobey the rules as the best solution for epistemology and philosophy of science (Feyerabend, 1975, p. 295-6).

In this view, the great revolution of science shows that science breaks the rules and it may not be advanced with no rules. Knowledge may be advanced with every rule, if it will be useful (Ibid, p.57-8). Feyerabend proves with many reasons that observational data and theories are not compatible and any effort for doing such work is not logical. In accepting theories, everything without any relation with that theory is useful. Feyerabend eliminates all the stable methods of epistemology and he believes that all of them blocks the works of scientists. According to this view, true epistemology is impossible and it shows that the epistemology is relative. In this attitude, science stables against magic.

\section{4) Structures of Science}

Research program is from Lakatos. His program has a hard core with a traditional hypothesis which would not be modified or abandoned. Every scientist who modifies the hard core world be eliminated from the specific research program. This hard core of program is rescue from failure by a power belt from assistant hypothesis. (Lakatos, 1974, p. 132-6)

Lakatos's program makes ready the positive and negative research heuristics. A positive heuristic includes rules which would be done and a negative heuristic includes rules which would not be done. In the view of Lakatos, against Popper, an incompatible exam with fundamental theories cannot breaks and eliminates the whole of program. Such exam can destroys a part of power belt (Ibid, p. 186).

There are many questions about research programs. For example, fundamental hypothesis are derived from which place? How is the relation of these hypothesis with the world? And so on.

\section{The Second Part: The Quality of a Tale and the Equality of Tale and Science}

According to the stated statements, we find out that a Copernican revolution occurs in the philosophy of science. Inductivism stands various theories on observation but according to falsificationism, structures of science and against method know theories as the action of human's mind. On the other hand, inductivism persists in object but its successors persists in subject. Doubtless, science is incompatible with inductivism and it should be seen as a myth and it must be eliminated. After destroying the induction, whatever could be its successors; Answers of a few famous schools and some of their failures are mentioned. A failure which suffer all of them is their one-side looking of them. According to this, I think that the point of view that "science is a tale" is a suitable successor for science and we consider it into two parts: A) the equality of structures of tale and science, B) the equality of themes of tale and science.

\subsection{The Equality of Structures of Tale and Science}

Whatever connect science to tale is the very close characteristics of them. A tale stands on search (Ne'matal-lahi, 2004, p. 52), and the aim of science is only search of truth. In the life of people, the tale have advanced equally with knowledge. The tale is repeat of a chain of sudden, wonderful, distinct and incredible episodes of real and unreal heroes about the ancient struggle between goodness and badness and also about usual victory of goodness over badness (Ibid, 52). The tale structure consists of five parts. Exposition by storyteller is the beginning of the tale. 
Hero's, time and place of the tale are introduced. time of the tale is unknown: in one day ...In many years before this time ... and also the place of it is unknown: in a far city ... in a dark forest...

In the second part we are confronted with raising a problem by the storyteller. Heroes encounter special problems here and this difficulty deepen the struggle, and conflict between good and evil hero. In the third part which is the tale's climax, the good hero endeavors for denouement and he wants to rescue audience from problem. The auditor is worried about what will occur and this suspense increases moment by moment as far as the hero solves the problem, then secret of the tale will be clear up for audience and this is the fourth part. In the fifth part we see falling action of the tale and it is end of climax. Then, it arrives at a calm and good end by the most extreme conclusion (Chambers, 2003 , p. 24 and 25). The tale is always prefaced peacefully and its conclusion is peace, too; and it always has a happy end. The storyteller and auditor with each other create a world in the tale stand up on words and ideas. (Ibid, $15)$.

There are further questions facing us, such as how a tale should be till it get appropriateness for being said to people? Whether the tale motivates a narrator to cause audience keep him company? Can the tale be explained to others well by its storyteller? Whether or not the tale has enough length and appeal (Ibid, 23)? We will response to these questions latter. Though, we need to know a storyteller should illustrate his tale necessarily just as a poet could not start his poem.

A tale consists of two sides. On the one hand narrator settles his idea, appealing statements and utterance which are combined with his mind and special method on the frame of the tales which connects with his soul and then explains it to audience; On the other hand, the audience' idea and imagination combine with the tale just as audience want (Ibid, 45).

Auditor in company with storyteller endure a tale -just as he himself wants - and he assumes that he was born with the tale's hero and his individuality grows and advances on length of the tale and just as the later hero is not the earlier hero who started the tale thus, auditor lives under many novel ideas that the narrator settles them on his way. (Vahidian, 1991, p. 264)

Narrator, in our tale, is an intellect who scatters his observation and knowledge seeds in the form of a tale in the field of audience' soul.

\subsubsection{Hero}

A tale have two hero at least. Hero in our tale are made in advance and they are strong, constant and good or evil hero. Good hero achieves intellect's desires (=narrator) and evil hero is enemy of the intellect's ideals. (Ne'matal-lahi, 2004, p. 52)

Let us compare one of tales of science with all of its tiny points: "the tale of the earth and the sun "or theories which as if the sun were at the center or the earth were at the center.

A number of hero - that are good hero every so often and then they become evil hero -who are in their usual struggle in the tale. The first hero is Ptolemaic theory who is the best and lovely hero with no rival at the beginning of the tale. His rivals are not capable of standing against him. But a hero always settles against another one. A young hero settles instead of an aged one. In spite of having equal power in many tales, it is not predictable who will be victor at the end. This equal strength increase the desire and suspense of an auditor and it caused him kept the tale company. Struggle between two heroes is more appeal in such tales (Vahidian, 1991, p. 271). In some tales a hero is more powerful than the others. He has a great tools of strength and support tools - just as Ptolemy's theory of " geocentrism "- was supported by the whole authority of the Church and kings; against him a rival hero from the view point of body power, money, social position and so many other abilities is in a lower level than the powerful hero, but he overcomes him by the superiority of idea. (Vahidian, 1991, p. 272). And in this way, the idea of Copernicus's creator wins at clearing up the failures of Ptolemy's theory; so, that strong hero and powerful conqueror changes to a lost cowardice and he is excommunicated and send out of the king's court. The tale's hero is stable and steady thus, the tale's hero has a constant individuality from the beginning to the end of the tale. They obey the rule of all or nothing and they deviated from a road of heroism by a complete failure. It is so in the world of theories; it means that the victorious theory is lost and abandoned only by one statement which is incompatible with structure and fundamental of the theory.

\subsubsection{Exposition}

A tale begins in this way "in one day" in "a far city" in "a happy calmness". The place and time of that tale are unknown. But as if the tale is contemporary with the auditor's life in the village and city of him. The tale of science 
has unknown beginning, too. Nobody knows who had made the first theory first time the tale begins on a popular calmness of scientific community. After that we see an alone, friendless and infamous hero in square of knowledge who states a statement that it makes the other powerful hero nervous.

\subsubsection{Struggle}

The good hero starts his action for arriving at his aim which is conquer rival theory and the evil hero stands against him for preventing from works of the youthful hero then, struggle between them begins. (Vahidian, 1991, p. 270) Without struggle and conflict not only the tale is not appealing but also any tale will not be built basically. A tale without conflict is not a tale, indeed. The struggle may occurs between two individuals or a person and its nature and forces or some time a person is in conflict with himself - as it occurs in "Boof e Koor". It appears that there are struggle between two theories (or their advocates) in science. To raise the struggle between heroes causes to advance of the tale. So, personal excitement and suspense among audience are seen. It is the tale's climax. The most serious struggle occurs in the tale's climax. (Vahidian, 1991, p. 274) The entrenchment of two rival's forces makes the tale's climax and it causes auditor keep the tale company until its conclusion and falling action.

In the tale of science, thousands of good and evil heroes array against each other. Struggle among Copernicans and Ptolemaic forces and then Galileo's armies and Copernicus's followers and victory of some to others caused to an eternal struggle. This struggle has been continued so far.

\subsubsection{Process of the Tale}

Nobody acknowledged the tale of a storyteller if he does not store his tale with wonderful and incredible matters. Progressive process of science has thousands of wonderful and incredible consequences in itself. In ancient time, to make a water which burns or to predict the eclipse of the moon and the eclipse of the sun could make people surprised as far as they repeated that story for many years. In modern time, science gives the universe many thousands of wonderful means like automobiles, home instruments, computer, Internet, airplane, camera and cine-camera; and there are so many initiatives nowadays so that individuals are not able to stand against them. Many observations of people of this time were dream in one or two hundred years ago.

\subsubsection{Raising a Problem, Suspense, Denouement}

Wherever that can predicts the future of a tale is its climax. Struggles are in their highest level. Auditor does not know who is a good hero and who is a bad hero. He never knows whoever will defeat and whoever will lose. The more powerful group (that probably is states of the old theories with more unstable bases) endeavor to conquer the modern and revolution group. Inquisition courts of Europe in the Middle Ages are the most important means on the hands of powerful people of church and olden theories. Those courts by means of execution and prison forced Copernican revolutionists to abandon the novel ideas and to gather with each other on square of novel theories and to release Ptolemaic olden theory. Galileo was in progress from being this tale's hero to hanging and then he rescued free himself by a trick.

Auditor of a tale, from the beginning of a problem to its denouement continuously asks himself: "what will occur?" this suspense between two rival theories motivates auditor and narrator to continue it. This part - from the time that a problem arise to denouement - is the most estimable part of a tale (Chambers, 2003, p. 25). Because a storyteller encounter many excitements and suspense here. Whether Galileo who attempted to eliminate the struggle and problem was not in such excitement? It may be better to say that all Roman judges of inquisition court, the intellect persons of that country and the people who were aware of the story have not this excitement and suspense? If a reader in this time dose not be aware of that court's result while reading the history of science, certainly he will be captured in the excitement and suspense even with clarity of Galileo's destiny and his final victory for him.

The struggle between two heroes, raising a problem, suspense and denouement in science will result in falling action and conclusion of a tale and the calmness comes to country of the tale again. For instance, before that Galileo had seen the moons of Jupiter by constructing a telescope, there were no struggle and conflict between two heroes (the first calmness); Galileo's statement about the being of the moons of Jupiter made his rivals nervous (struggle). They took into account error of Galileo's telescope as the creator of the moons of Jupiter (raising a problem). Galileo argued reasonably that if these are consequences of that error, they would be seen around of other stars. Then, why they are seen only around of Jupiter? (Denouement). After the powerful reasoning of Galileo and creation of more powerful telescopes, Galileo's theory conquered the previous theories that believed Jupiter is free from the moon (falling action and conclusion ).And this theory governed the world of science with happiness for many years.

There are such examples in a very high frequency in the history of the tale of science. Indeed, science is a tale like the tale of "Tu dar Tu" which is notable in storytelling in the Indian style. "Kelileh va Demneh," Masnawi va 
Ma'nawi", "Manteq Al-teyr" and "Hezar va Yek Shab" are the most notable examples of this kind of tales. There are probably thousands of shorter tales into the general tale in these kinds of tales, just as there are thousands of such examples in the tale of science.

There is another example like the examination of "the tower". The nature of science is in a popular calmness before that Copernicus had ignored Ptolemaic theory of "geocentrism" and placed the theory of "heliocentrism" instead of it (the first calmness). But Copernicus by expressing the theory of "heliocentrism" made the asleep universe nervous and he challenged his rivals (struggle). When Copernicus reasoned that the earth revolved around the sun, his rivals made a powerful reasoning which is called "the tower". Here is that reasoning:

"According to Copernicus, if the earth revolves around itself, everywhere on the earth would travel long distances per second; if a stone is felt from top of a tower on the round earth, it shall fall to its centre because of its natural motion. To fall the stone happens in contemporary with the tower's motion. Hence, while arriving the stone to the earth the tower has moved from where the stone starts falling. But it will not occur in practice; the stone falls to the earth beside of the tower. When we consider falling the stone to beside of the tower we observe that the earth cannot turns, so the Copernicus's theory is not true" (denouement). After many years (suspense), scientists came and went and then Galileo could break this mechanical reasoning of his rivals through the reasoning of ship mast although , Copernicus himself had not the ability of expressing an appropriate response to his rivals. That reasoning was in this way that if we release a stone from the top of a ship, the stone would fall besides of the mast, though that ship is going very fast on the sea. The motion of the ship or stopping it does not effect on falling stone; because the stone move in contemporary with the ship in a equal rate. And also the stone which is felt from the top of the tower revolves around the centre of the earth (or the sun) with that same rate. Because of this subject, the stone would contact with the earth (denouement), the rivals of the theory of Copernicus had to release their theory and acknowledged the Copernicus's theory (falling action and conclusion). After that time, the Copernicus's theory was about revolving the earth around itself and the sun has governed the universe of knowledge (the final calmness).

\subsubsection{Theme}

The theme of tales adjusts to the nature of storytellers (Chambers, 2003, p. 22). It means that every storyteller selects the collection of tales which are more adaptable to the nature of his taught subjects.

\subsubsection{The Aim and Main Idea of a Tale}

The first aim of a tale is probably "creation" because "the time of creating a tale is the time of two-side creation" (Chambers, 2003, p. 15). But a story teller would be well-informed that he does not eliminate the ability of two-side creation with being captured by storytelling tools (Ibid, 46).

Another aim of the tale is entertaining people. Whether all science functions in this world are not the conjuration?

The third aim of the tale is denouement of the nature. The most valuable aim of a scientist about science is probably to understand "what is the nature and how does it work?"

The fourth aim of the tale of science is to benefit of natural forces of the nature. To benefit of water which gathers behind dams, to get electricity from the sun, to build power plants that work by waves of the sea, gas, oil and nuclear energy. All these matters help in arriving at this aim.

And also we can add other aims of the tales like truth and ethics training. Advice may be another aim.

\subsubsection{Another Statement}

The utterance of tales is more serious just as the intellects are who serious in expressing their statements; superman and superhuman logic governs theme of tales so, credibility and intellect of most of the tales is low.

\subsection{The Equality of Themes of Tale and Science}

It is better to consider deeply. The ancient tale of for better understanding of the equality of themes of tale and science. In tale the things like and ..... are out of my mind. Surely (realism) of these things, in itself, have stable relations with each other. (Absolutism) against these things, is a thing in my name who think. So, science has two structures. The world and I. The world on its real identity would not be known for me because I get it by sense and I should feel it consequently whatever I know about the world is "my world". I (=subject and intellectual person) has loves and hates, wills, aims and needs on one side. And, the world is not for me as it is on the other side. I suppose relations among things on the world based on measure of my knowledge about the world, wills and soon these relation which are called scientific (aws and theories are products of being visible external things and my internal tendencies ( $=$ subject and intellectual person) the inner tendencies are three kinds: knowledgeable tendencies (the 
application of stability of mind on stable things ), artistic tendencies ( the creation of soul in itself )and biological (the things which are suitable for remaining). Haman's mind has stable certain knowledge, such as statements of mathematical logic and ...... we have stable knowledge about material world, Too one of these knowledge is being of some relations between external things, based on wisdom and logic, but we do not know is the relation between "Gav " and "hasan", because they are revolutionized continually. I give you an example for clarifying this subject: In the point of view of Descartes, on object is only the length, width and depth. This is a certain and stable knowledge. But, what is the length, width a depth of this pen? And how received to a real knowledge about it (and all other things)? It is depended on being of the pen and internal tendencies specially, my tendency to knowledge. In accordance with it, I suppose relations many things but I destroy those relations and create novel relations, I create many theories about the world and I suppose that I know it by every law and when I defeat, I suppose it is a bridge for really knowing of the world.

\section{Conclusion and Suggestion}

Science structure is wonderfully similar to tales of grandmothers for putting to sleep their grandchildren. We can take into account science as a long tale which is made by storytellers (scientists) for amusing and putting to sleep children (people). And there are many thousands of short or long stories within this long tale. Commensurable critique of schools of epistemology of science is commendable but their inability to real knowledge of the how and the why of science is their failure. It is suggested the readers, without personal tendency, firstly, consider this thesis which "science is a universal tale"; Secondly, compare it with other epistemological schools; and thirdly, critique various examples of theories of science and various tales.

Acknowledge of this thesis will result in advancement of science in the future, all knowledge will be human sciences and the struggle between them will be eliminated.

\section{References}

Burtt Edwin Arthur. (1990). The Metaphysical Foundation of Modern Science. Translated by Abdul Karim Soroush, Scientific-Cultural Publications, Tehran.

Chalmers A. F. (1976). What is this thing called Science? University of Queensland press.

Chambars. (2003). Storytelling and Creative Play. Translated by Soraya Ghezel Ayagh, University Press, Tehran.

John Losee. (2001). A Historical Introduction to the Philosophy of Science (3rd ed.). Translated by Ali Paya, Samt, Tehran. Oxford University Press: USA.

Ladyman, James. (2002). Understanding the Philosophy of Science. London and New York: Routledge.

Lakatos. (1974). IMRE Falsification and the Methodology of Scientific Research Programmes, in Criticism and the Growth of Knowledge. Cambridge: Cambridge University Press.

Lazy, John. (2006). A Historical Introduction to the Philosophy of Science. Translated by Ali Paya, Samt, Tehran.

Nematollahi, Faramarz. (2004). Child and Adolescent Literature (Identification, Evaluation, Appraisal). Ministry of Education, Tehran.

Paul K. Feyerabend. (1975). Against Method: Outline of an Anarchistic Theory of Knowledge. London: New Left Books.

Popper, Carl Raymond. (1991). The Logic of Scientific Discovery. Translated by Seyyed Hossein Kamali, Scientific-Cultural Publications, Tehran.

Vahidian, Kamyar, Taghi. (1991). New words in Persian literature. Chamran University, Ahvaz. 